\title{
PARTISIPASI PETANI DALAM PEMULIAN STEVIA (Studi Kasus di Kelompok tani Mulyasari Ciwidey Kabupaten Bandung)
}

\author{
Yayat Sukayat, Hepi Hapsari, Pandi Pardian, Dika Supyandi
}

Staf Pengajar Fakultas Pertanian Unpad

\begin{abstract}
ABSTRAK
Kebutuhan gula pasir yang bersumber dari tanaman tebu (Sacharum oficinarum L) untuk konsumsi rumah tangga dan industri pada tingkat nasional menempati posisi kedua setelah beras. Ketidakmampuan produksi nasional memaksa pemerintah membuka kran impor gula pasir untuk memenuhi kekurangan. Namun tetap saja kurang, sehingga ada indikasi industri makanan/minuman menggunakan gula sintetis. Oleh karenanya, tumbuh keinginan masyarakat untuk mencari alternatif pemanis alami berkalori rendah. Salah satu sumber pemanis tersebut adalah tanaman stevia (Stevia rebudiana). Namun hingga saat ini, pengembangan stevia nasional terkendala oleh ketersediaan benih. Peneliti dan pemulia Unpad melakukan rekayasa genetika stevia melalui induksi mutasi sinar gama dalam rangka menjawab kebutuhan tersebut. Agar komoditas ini adaptif dan sesuai dengan kebutuhan pengguna, pemulia melibatkan masyarakat dalam pengembangannya. Tujuan dari penelitian ini adalah untuk mendeskripsikan keterlibatan/partisipasi pengguna dalam pengembangan benih stevia hasil rekayasa tim Unpad, mengkaji faktor-faktor yang ada hubungannya dengan partisipasi petani dalam pengembangan stevia, dan menelaah faktor-faktor yang menjadi pertimbangan dalam penggunaan benih stevia Unpad. Penelitian ini adalah penelitian kualitatif deskriptif dengan teknik studi kasus. Hasil penelitian menunjukkan bahwa partisipasi petani dalam pengembangan benih stevia adalah dalam bentuk ide/gagasan, kontribusi fisik dan kontribusi finansial. Partisipasi tidak terlepas faktor dukungan koperasi yang berfungsi sebagai penampung hasil, kelompok sebagai tempat belajar, dan petani anggota sebagai pelaku yang menjaga kuantitas dan kualitas produksi. Penggunaan benih stevia Unpad dipertimbangkan jika secara teknis stevia yang dikembangkan berumur pendek, memiliki rendemen gula yang tinggi, adaptif terhadap lingkungan, serta memiliki cabang yang cukup banyak.
\end{abstract}

Kata kunci: pemuliaan stevia, partisipasi petani

\begin{abstract}
The need for sugar sourced from sugar cane (Sacharum oficinarum L) for household and industrial consumption at the national level occupies the second position after rice. The inability of national production forced the government to import sugar in order to meet the shortage. Import has not solved the problem, even there is an indication that food/beverage industries used synthetic sugar. Hence, desire of the community to find alternative natural low-calorie sweeteners has been growing. One of the sources of sweetener is stevia (Stevia rebudiana). Unpad researchers and breeders genetically modified stevia through induction of gamma rays in order to answer these needs. In order for this commodity to be adaptive and in accordance with the needs of users, breeders involved the community in its development. The purposre of this study was to describe the involvement/participation of users in the development of stevia seeds engineered by Unpad team, to examine factors that have to do with farmer participation in the development of stevia, and to study the factors that are considered in the use of Unpad stevia seeds. This research is descriptive qualitative research with case study techniques. The results showed that farmers' participation in the development of stevia seeds was in the form of ideas, physical contributions and financial contributions. Participation cannot be separated from several factors, namely the cooperative support, which functions as a place of results, the farmer group as a place of learning, and member farmers as actors who maintain the quantity and quality of production. The use of Unpad stevia seeds is considered if technically, developed stevia is short-lived, has a high sugar yield, is adaptive to the environment, and has quite a lot of branches.
\end{abstract}

Keywords: stevia breeding, farmer participation 


\section{PENDAHULUAN}

Konsumsi gula per kapita masyarakat Indonesia rata-rata mencapai $6,8 \mathrm{~kg} /$ capita /tahun, atau berkisar a ntara $8 \mathrm{~kg} /$ capita /tahun pada tahun 2007 menurun menjadi 6.2 $\mathrm{kg} /$ capita/tahun pada tahun 2015. Secara perkapita kebutuhan gula ini menunjukkan penurunan, namun secara kumulatif dengan pertumbuhan penduduk yang masih relatif tinggi, kebutuhan gula pasir pertahun mencapai 5,7 juta ton, lebih tinggi dari produksi nasional yang hanya mampu menghasilkan gula tebu sebesar 2,2 juta ton. Tingginya kebutuhan gula ini membuka peluang dan mendorong adanya para pelaku usaha industri makanan jajanan menggunakan gula syntetis menggantikan gula tebu alami sebagai pemanis, dan pada saat yang bersamaan Pemerintah, melalui kementrian perdagangan mengijinkan untuk impor gula pasir sebanyak 3,22 juta ton. Walaupun pada kenyataannya impor ini belum bisa memenuhi kebutuhan konsumsi, . Fenomena ini sungguh menuai perhatian dan kehawatiran dari masyarakat,sehingga muncul alternatif mengembangkan pemanis alami berkalori rendah dari tanaman stevia (Budiarso,2008) .

Stevia (Stevia rebudiana), dari family

Asteraceae, yang tumbuh baik di daerah tropis dan subtropis memiliki beberapa keunggulan, diantaranya tingkat kemanisannya mencapai 200 - 300 kali dari gula tebu, dan kadar kalorinya relatif rendah (Maudy,1992). Ternyata tumbuh kembang dengan baik pada agro ekosistem Indonesia, khususnya di Jawa Barat . yang secara umum memiliki bentang alam dari dataran, perbukitan dan pegunungan. Kondisi ini cocok untuk stevia, karena secara agronomis stevia lebih cocok ditanam di daerah dataran tinggi, dengan ketinggian di atas $1000 \mathrm{~m} \mathrm{dpl}$, dengan lama penyinaran kurang dari 12 jam. Produksi gula yang terus menurun sebagai dampak menurunnya luas lahan tebu (Shacharuum oficinaruum L), dan kondisi agro ekosistem yang memadai untuk tumbuh kembang stevia, ketika dipadukan akan menjawab keterbatasan produksi gula alami dari tebu.

Pada tahun1984, Stevia di Indonesia baru tahap penelitian yang dilakukan oleh Balai Penelitian dan Perkebunan (BPP)/atau Balai Penelitian Biotektonogi Indonesia.dan menghasilkan Bibit Unggul Klon pada tahun 2013. Dan yang di unggulkan yaitu BPP 72. Penyebaran dilakukan di Jawa Barat (di Ciwidey Bandung, Garut dan Bogor) dan Jawa Timur (di Tawang mangu). Namun di tingkat petani dalam pengembangan stevia sebagai alternatif gula alami, tidak terlepas dari persoalan yang mendasar, yaitu persoalan bibit. Bibit yang diperoleh dari biji (Generatif) sulit untuk mendapatkan galur murni, karena memiliki sifat "self incompatable", dan memiliki daya kecambah yang rendah (Felippe et al,1977), serta produktivitasnya rendah ,Lee et al,1979. lebih lanjut perbanyakan secara vegetatif pun tidak luput dari masalah yaitu rentan dari kegagalan ketika dipindah tempatkan. Solusi yang relatif aman yaitu menggunakan metode kultur jaringan.

Unpad tanggap dengan kondisi tersebut, Suseno Amin dkk,2015. mencoba melakukan rekayasa genetika melalui metode mutasi in vitro sinar gama,yang menghasilkan varietas unggul seperti :

1. Kode tanaman B5A2 aksesi Bogor yang diradiasi sinar Gamma 5 Gy

2. Kode tanaman BEA3 aksesi Bogor diberi perlakuakn EMS 0,5\%.

3. Kode tanaman G3.5B2 aksesi Garut yang diradiasi sinar Gamma 3,5 Gy

4. Kode tanaman G5.BA2 aksesi Garut yang diradiasi sinar Gamma 5 Gy

5. Kode tanaman G7.5A2 aksesi Garut yang diradiasi sinar Gamma 7,5 Gy

6. Kode tanaman T3,5B2 aksesi Tawangmangu diradiasi sinar Gamma 3,5 Gy

7. Kode tanaman TED1 aksesi Tawangmangu yang diberi perlakuan EMS 0,5\%

Secara laboratorium hasil tersebut sudah teruji baik di ruangan maupun dilapangan, namun ditingkat petani belum dilakukan. Mengingat pada gilirannya masyarakat, baik sebagai petani produsen yang terus bersentuhan dilapangan, dan industri sebagai pengguna yang mewakili konsumen yang banyak memanfaatkannya, maka dalam pengembangannya menuntut keterlibatan para pengguna tersebut. Melalui pendekatan Plant Breeding Participation, menempatkan peneliti sebagai leader, sehingga dalam mengembangkan stevia dilakukan dalam bentuk invention. Hal ini 
penting dilakukan, karena melalui partisipasi pengguna akan menghasilkan informasi yang bisa dikomunikasikan ke pemulia,agar dihasilkan benih yang adaptif sesuai dengan lingkungan dan kapasitas petani serta kebutuhan pengguna lainnya. Timbul pertanyaan bagaimana keterlibatan pengguna dalam pengembangan benih stevia hasil rekayasa tim unpad; Faktor soaial ekonomi apa saja yang ada hubungannya dengan keterlibatan petani dalam pengembangan stevia; dan apa yang menjadi pertimbangan dalam penggunaan benih stevia unpad.

\section{METODE PENELITIAN}

Penelitian ini merupakan penelitian deskriptif kualitatif, dengan teknik penelitian study kasus kelompoktani Mulyasari Kecamatan Pasir Jambu Kabupaten Bandung Jawa Barat. Dalam penelitian ini lebih besifat interpretatif (Sugiyono 2012) dan mendalam pada satu unit analisis baik individu maupun kelompok (Rusidi,1993)

Data yang digunakan dalam penelitian ini meliputi data primer dan data skunder. Data primer diperoleh dari hasil wawancara dengan pengurus kelompok tani dan anggota yang laiinya, sedangkan data skunder diperoleh dari informan yang mengetahui pasti tentang kegiatan pada kelompoktani mulyasari; dekumentasi; dinas intansi terkait dan dari literatur.

Teknik pengumpulan data dilakukan melalui observasi, yaitu melalui pengamatan langsung di lapangan untuk mendapatkan informasi tentang fenomena/masalah yang terkait dengan kelompok tani dalam pengembangan stevia; wawancara, yaitu penggalian informasi yang dilakukan kepada para pelaku usahatani stevia, anggota, dan pengurus kelompok mulyasari; diskusi kelompok, untuk mengajegkan informasi yang di peroleh; dan study pustaka melalui data-data yang ada pada kelompok tani, desa/kecamatan, kantor penyuluhan dan dinas intansi terkait.

Rancangan analisis data adalah analisis deskriptif kualitatif, yang mengacu kepada identifikasi sifat-sifat yang membedakan atau karakteristik sekelompok manusia, benda, atau peristiwa. Intinya dalam deskripsi kualitatif dilakukan proses konseptualisasi dan menghasilkan pembentukan skema-skema klasifikasi (Silalahi, 2012).
HASIL DAN PEMBAHASAN. Partisipasi Petani dalam Pengembangan Stevia.

Keterlibatan atau partisipasi petani atau pengguna dalam pengembangan benih stevia, baik sebagai petani produsen (pengembang bibit sebar) maupun sebagai konsumen yang menghasilkan produk jadi (industri/perorangan), merupakan komitmen dari pengguna, untuk menghasilkan benih /bibit yang sesuai dengan kebutuhannya,konsef ini merupakan bagian dari pengembangan benih secara partisipasi (participatory plant breeding). Keterlibatan atau orang sering menyebutnya partisipasi, merupakan suatu proses penyerahan diri yang didukung oleh tanggung jawab guna tercapainya kegiatan yang sedang dilakukan dan berkelanjutan. Keterlibatan seseorang untuk mendukung kegiatan bersama untuk kepentingan bersama, bisa muncul dalam bentuk gagasan, aktivitas maupun financial mulai dari perencanaan, operasi dan pemeliharaan, sampai evaluasi. Ada hal-hal yang bisa di tegaskan, dari partisipasi, pertama keterlibatan seseorang karena atas suatu kegiatan yang datang dari luar bisa memaksa ataupun tidak, dengan harapan akan memberikan keuntungan ekonomi sosial, maupun budaya; ke dua ketrelibatan terhadap kegiatan yang dirancang bersama,untuk kepentingan bersama. Keterlibatan pengguna dalam pengembangan benih secara partisipasi, ada dua hal yang menjadi perhatian yaitu tujuannya, dan siapa yang memimpin apakah pemulia atau petani (farmer led atau formal led) (Supyandi, dkk, 2016).

Keterlibatan petani pengguna dalam pengembangan stevia, di aktualisasikan dalam bentuk fisik, ideu dan financial, dari mulai, perencanaan, pengorganisasian, pelaksanaan sampai dengan evaluasi. Kelompoktani mulyasari, merupakan bagian dari (Lembaga Masyarakat Desa Hutan) atau LMDH, dan berafiliasi juga dalam koperasi nukita, aktivitasnya tidak hanya mengandalkan stevia sebagai komoditas andalan, tapi banyak komoditas yang di usahakan termasuk kopi. Dari jumlah anggota 165 orang, hanya 25 orang $(15 \%)$ yang merespon dan mau terlibat dalam pengembangan stevia, baik secara monoculture, maupun berupa tumpang sari, 
yang luas keseluruhan mencapai $2 \mathrm{Ha}$. Jumlah tersebut dari mulai dikembangkan pada tahun 2010 sampai dengan sekarang tidak pernah mengalami perubahan. ternyata banyak faktor yang melatar belakangi keputusan petani terlibat dalam pengembangan stevia, baik yang berasal dari tataran individu (mikro), kelembagaan kelompok (meso), maupun tataran (makro) terkait regulasi

Ketika stevia ini di sosialisasikan, dalam perkembangannya mengikuti sifat inovasi, seperti apakah menguntungkan , sampai dengan mungkin tidaknya di usahakan. Dengan menggunakan analisis sifat inovasi dari Margono Slamet (1978) yang dikutip oleh Totok Mardikanto (1982), adalah sebagai berikut:

Tabel 1. Alasan terlibat dan tidak terlibat dalam pengembangan stevia

\begin{tabular}{|l|l|l|}
\hline Sifat Innovasi & Alasan & \multicolumn{2}{|l|}{} \\
\cline { 2 - 3 } & $\begin{array}{l}\text { Telibat } \\
\mathrm{n}=25 \\
\text { orang }\end{array}$ & $\begin{array}{l}\text { Tidak } \\
\text { terlibat } \mathrm{n}= \\
140 \text { orang }\end{array}$ \\
\hline $\begin{array}{l}\text { Keuntungan } \\
\text { relatif }\end{array}$ & + & - \\
\hline Kompatibilitas & + & - \\
\hline Kompleksitas & + & + \\
\hline Trialibilitas & + & + \\
\hline Observabilitas & + & - \\
\hline $\begin{array}{l}\text { Ketersediaan } \\
\text { input }\end{array}$ & + & - \\
\hline
\end{tabular}

Alasan mikro petani terlibat atau tidak terlibat dalam pengembangan stevia, pertama adalah menguntungkan atau tidaknya, dalam tteori pertukaran dikenal dengan Reward lebih besar dari Cost $(\mathrm{R}>\mathrm{C})$,Homans, para petani yang tidak terlibat, umumnya mengatakan ....pak, kanggo petani melak naon bae tiasa, nu penting aya pasarna, kalayan hargana kahartos, aya leuwihna... artinya bagi petani tanam apapun bisa yang penting ada pasar dan harganya menguntungkan.. memang pada kenyataannya Koperasi Nukita, sebagai kelembagaan yang menampung produk stevia dari petani kemampuannya masih sangat terbatas. Sehingga tidak merangsang petani lain untuk ikut serta dalam mengembangkan stevia. Kedua, Keterlibatan petani dalam pengembangan stevia ini terkait dengan akses terhadap lahan. $85 \%$ petani (140 orang) umunya mengelola lahan milik perhutani, yang jaraknya kurang lebih $4 \mathrm{~km}$ dari pemukiman, sedangkan sisanya $15 \%$ (25 orang) selain mengelola lahan perhutani sebagian milik sendiri, jaraknya antara $500 \mathrm{~m}$ sampai dengan $1 \mathrm{~km}$. Hal inipun salah satu dasar ketika petani mengambil keputusan untuk berpartisipasi (Adiwilaga, 1973). Selain bangun usahatani, jarakpun berpengaruh terhadap kegiatan usahatani. "garapan abdimah tebih $P a$, kirang langkung $4 \mathrm{~km}$, benten sareng anu sanes nyaeta nu melak stevia jarkna oge mung satengah kilo dugi ka skilometer, janten upami bade nyebor, ngagemuk teu sesah, sedengkeun nu abdi tiasa dibayangkeun ku bapa kedah mikul pupuk kandang pisabarahaeun ongkosna...". "lahan usahatani yang kami usahakan jaraknya cukup jauh kurang lebih $4 \mathrm{~km}$ beda dengan yang lain hanya sekitar satu kilo meter, sehingga tidak menyluitkan pada saat penyiraman dan pemupukan, sedang punya kami bisa bapa bayangkan, dan pada gilirannya akan berdampak pada biaya".

Selain jarak terhadap lokasi kegiatan, indikator akses agribisnis yang memiliki peranan dalam kesungguhan petani terlibat dalam pengembangan stevia, yaitu status dan luas penguasaan lahan. Dari hasil observasi dan penelusuran ternyata sebagian besar petani yang tidak ikut serta dalam pengembangan stevia menguasai lahan kurang dari 0,5 Ha dengan status penggarap (milik perhutani). Kepastian hukum terhadap lahan, memiliki peran dalam mengambil keputusan berusahatani. Petani sebagai penggarap lahan milik perhutani, dalam melakukan tindakannya harus mengikuti aturan main yang ada pada lembaga,baik lembaga berupa Kelompok tani, Lembaga Masyarakat Desa Hutan (LMDH), dan Perhutani. Aturan main yang disepakati oleh lembaga-lembaga tersebut yaitu : (1) petani yang mengelola lahan dengan kemiringan di atas $15 \%$ hanya diperkenankan untuk menanami lahannya dengan tanaman industri (kopi), dan kayukayuan; (2) kalau di antara petani akan memanfaatkan lahan di antara tanaman dengan komoditas hortikultura atau sejenisnya, guludan tidak boleh menggunakan penutup tanah (mulsa). Aturan main inilah yang mendorong $85 \%$ petani, tidak mengusahakan stevia. Seperti yang disampaikan petani: "lahan nu di kelola ku abdimah tebih, hampir $4 \mathrm{~km}$, sareng rada 
curam... kanggo ngajagi kualitas hasil stevia guludannana kedah di tutup mulsa, tapi kan teu kenging bilih longsor...sarengna lahanna oge tos hieum ku kopi..sarengna deui teu acan biasa..."-"Dengan memperhitungkan jarak, dan aturan dalam pemanfaatan lahan perhutani (di lahan miring lahan dilarang menggunakan mulsa), luas penguasaannya relatif sempit, serta kerapatan tanaman kopi yang di usahakan, menurutnya usaha stevia tidak menguntungkan". Selain pasarnya yang belum jelas. Sebaliknya, pada petani yang terlibat, mereka menghitung dari curahan waktu (waktu pemeliharaan sekitar 1 jam untuk menyiram) dan biaya relatif ringan(bibit disediakan oleh kelompok), karena jarak yang relatif dekat serta kondisi lahan yang relatif landai, dan tidak ditanami kopi, pasarnya sudah jelas (daun basah dibeli oleh koperasi dengan harga Rp 3 000,00/kg), usaha stevia ini menguntungkan.

Bagi petani yang tidak terlibat, stevia termasuk komoditas baru di kalangan petani, sehingga belum terbiasa untuk mengusahakannya. Terlebih lahan usaha mereka umumnya memiliki kemiringan yang cukup curam 15-30 \% bahkan lebih. Makin miring lahan usahanya, makin padat tanaman kopinya, sehingga kurang baik untuk pertumbuhan stevia, atau tidak kompatibel (Mardikanto, 1982). Sedangkan petani lain yang terlibat, lingkungan tidak menjadi persoalan, karena : (1) mereka sudah cukup lama mengenal stevia semenjak adanya kerjasama dengan vietnam tahun 2008; (2) lahan yang di usahakan sebagian besar lahan milik, dengan kondisi landai.

Secara makro stevia kurang populis, karena dukungan regulasi dari pemerintah, belum ada. Sehingga membuat hawatir para petani yang menanam, termasuk petani yang akan mulai mencoba menanam stevia. Dibukanya pintu impor gula tebu, bukan hanya membuat keruh kondisi pergulaan di indonesia, tapi juga tidak merangsang petani untuk menjadikan stevia sebagai alternatif pengganti gula alami yang terbuat dari tebu.

Dalam pengembangan stevia unpad di kelompoktani, melibatkan beberapa kelembagaan, seperti Unpad penyedia sumber bibit stevia hasil mutasi, Koperasi Nikita penjamin pasar, dan kelompok tani sebagai tempat pengembangan dan penguatan petani. Pengembangan stevia ditingkat petani hanya melibatkan anggota kelompok yang mengusahakan stevia sebanyak 25 orang $(15 \%)$. Keterlibatannya mulai dari perencanaan, pelaksanaan (operasi dan pemeliharaan), dan evaluasi.

Dalam perencanaan, seluruh petani anggota kelompoktani yang menanam stevia ikut hadir (100\% hadir), keterlibatannya diwujudkan dalam bentuk ide seperti menentukan waktu, tempat dan pelaksanaan tanam. Waktu tanam disepakati dipenghujung kemarau yaitu bulan juli agustus, dengan perhitungan dan pengalaman petani di bulan september sudah turun hujan, seperti yang disampaikan para petani: "biasana nu atosatos upami sasih agustus ahir atanapi awal september hujan tos ngawitan lungsur" "Dengan demikian, ketika tanam dilakukan pada bulan juli agustus, maka petani hanya memerlukan waktu dua bulan untuk menyiram tanaman, artinya effisien dalam biaya". Untuk menambah keyakinan petani, terlebih dahulu dilakukan petak percontohan (demplot). Tempat pelaksanaan disepakati menggunakan lahan petani yang jaraknya tidak terlalu jauh dari rumah petani (kurang dari $150 \mathrm{~m}$ ). "kanggo tempatmah atos nganggo nu patani bae,nu tempatna caket teu tebih teuing supados nyebor sareng ngontrol teu sesah...". Untuk membuat percontohan, karena melibatkan petani sebaiknya menggunakan lahan petani yang dekat,agar mudah dalam menyiram dan mengontrol. Hal ini mengindikasikan efektif dan efisien sudah menjadi perhitungan petani dalam merencanakan aktivitas, Max Weber menyebutnya sebagai bentuk tindakan yang rasional.

Dalam operasi dan pemeliharaan sebagai wujud konkrit dari pelaksanaan, tidak langsung elibatkan petani penanam stevia secara keseluruhan, tetapi cukup diwakili oleh tiga orang (12\%) yaitu keua, sekretaris dan bendahara. Keterlibatan mereka dalam pelaksanaan ini yaitu memberikan kontribusi dalam bentuk financial berupa peminjaman lahan usaha seluas $1000 \mathrm{~m}^{2}$ dan biaya tenaga kerja dalam pengolahan lahan dan pemeliharaan, mulai dari pemupukan, penyiangan dan penyiraman. Cara tanam untuk stevia Unpad ini, dilakukan secara monoculture, berbeda dengan stevia yang mereka miliki yaitu ada yang policulture atau ditanam disela-sela pohon kopi. 
Melalui demplot ini selain sosialisasi kepada petani, juga diharapkan diperoleh bibit yang adaptif dengan lingkungan petani. Oleh karena itu pemupukan menggunakan pupuk yang biasa petani gunakan seperti menggunakan pupuk dari kotoran domba dan ayam. Seperti yang dikemukakan petani: "didieumah pak upami melak stevia tara nganggo gemuk toko cekap ku tai hayam atawa kotoran domba, paling upami kapaksa nya dipasihan gemuk toko eta oge sakedik pisan, paling tina nu $1000 \mathrm{~m}^{2}$ cekap sakilo NPK..." - "disini kalau tanam stevia tidak pernah menggunakan pupuk dari toko, cukup dengan kotoran ayam dan domba, kecuali kalau terpaksan biasanya dari $1000 \mathrm{~m}^{2}$ cukup $1 \mathrm{~kg}$ NPK". Jumlah pupuk kandang yang digunakan $200 \mathrm{~kg}$ kotoran ayam, dan $200 \mathrm{~kg}$ kotoran domba.

Petani yang lain $(88 \%)$ terus memonitor dan mengevaluasi perkembangan tanaman. Secara tidak langsung telah terjadi diferensiasi peran dantara anggota kelompok. Evaluasi penting dilakukan untuk menghasilkan benih yang adaptif dan sesuai selera perani. Dalam pengembangan stevia unpad, posisi peneliti atau pemulia adalah sebagai pemimpin, yang menawarkan hasil karyanya kepada petani untuk dinilai dan pada gilirannya direkayasa kembali sesuai masukan dari pengguna dilapangan. Evaluasi dilakukan terhadap perkembangan, pertumbuhan bibit stevia yang sedang dikembangkan oleh kelompok tani, mulai dari pembibitan sampai dengan pertanaman dilapangan. Hasil evaluasi terwujud dari hasil persepsi pengguna yang terkontruksi dari penglihatan yang penuh interpretasi hingga terbentuk tanggapan (Morgan, 1966). Dan tanggapan atau persepsi bentuk partisipasi evaluasi berhubungan dengan kedalaman visual, seberapa banyak objek yang dapat dilihat (Hebb, 1972).

Keputusan petani dalam pengembangan stevia ini pada gilirannya akan jadi pertimbangandalam melakukan rekayasa genetika khusus untuk stevia.

Dari hasil evaluasi yang dilakukan oleh petani pengguna dan pengurus koperasi sebagai pemanfaat,diembiitan, umumnya pertumbuhannya baik, hanya batangnya agak lemah seperti yang di sampaikan petani: "ari ningal tina jadinamah sae, mung hanjakal leuleus, kirang kiat, sareng ngageleceng teu aya cabang, katambih daunna ipis...".

Evaluasi berikutnya dilakukan di kebun, dengan mengunakan jarak tanam 25 x $25 \mathrm{~cm}$, ternyata cabangnya kurang dan daunnya tetap tipis. Bagi petani kondisi ini kurang bagus karena terkait dengan produksi,dari hasil panen produksi pertama perpohon hanya mampu $0,3 \mathrm{~kg}$ dan kedua antara $0,3 \mathrm{sd} 0,4 \mathrm{~kg}$ sedangkan produksi yang biasa mereka peroleh per pohon bisa mencapai $0,5 \mathrm{sd} 07 \mathrm{~kg}$ atau jauh berbeda dengan produksi yang diperoleh ketika ditanam di laboratorium yaitu $0,8 \mathrm{sd} 1,2 \mathrm{~kg}$ sedangkan menurut pemanfaat (koperasi nukita) daun kecil dan tipis akan berpengaruh pada rasa, yaitu rasa manisnya kurang. Dari uraian tersebut di atas dalam pengembangan stevia, partisipasi petani akan memberikan kontribusi dalam rekayasa genetika sesuai kebutuhan petani, sehingga diperoleh benih yang adaptif, yang sesuai dengan kebutuhan lingkungan dimana mereka berada.

\section{Faktor Sosial Ekonomi petani yang}

Keberhasilan dalam pengembangan stevia sangat tergantung kepada partisipasi semua pihak, baik itu koperasi, kelompok maupun petani. Kualitas, kuantitas dan kontinuitas dari komoditas tersebut, perlu dukungan ke tiga elemen tadi. Kerjasama yang baik antara koperasi nukita sebagai lembaga pemasaran, dengan kelompok tani sebagai tempat belajar, kerjasama dan kerjasama pemasaran, dan petani sebagai pelaku utama di tingkat hulu, yang berupaya menghasilkan produksi yang tinggi, dalam pengembangan benih yang adaptif, sesuai lingkungan dan kebutuhan pasar sangat diutamakan. Ketika koperasi berbuat ditingkat hilir, maka petani akan berupaya meningkatkan kuantitas dan kualitas produksi ditingkat hulu, dan kelompok meminage proses produksi agar produksi berkelanjutan.

Pada saat pengembangan stevia yang berujung pada terciptanya benih yang adaptif (tujuannya menghasilkan benih/bibit yang adaptif), kunci utama sangat bergantung kepada partisipasi petani sebagai pelaku utama, yang terjun langsung dalam proses produksi. Parson melihat setiap tindakan manusia selalu diarahkan pada tujuan, dan nilai lain akan jadi pengarah dalam proses 
pencapaian tujuan tadi. Di lapangan nilai lain sebagai pengarah ini berupa aspek sosial ekonomi, yang selama ini menjadi pendorong untuk berpartisipasi. Aspek sosial, yang mendorong petani untuk berpartisipasi, lebih kepada eksistensi lokasi , dan ketergantungan pada koperasi nukita. Seperti yang disampaikan petani: "sateu acan dinu sanes stevia dikembangkeun di cibodas, abdi sering kasumpingan tamu ti luar jawa , $t i$ jawa kalebet garut kanggo di ajar stevia. Sok sanaos di abdi nyalira stevia sanes utama, nu utamanamah kana kopi..."-“"sebelum di tempat lain stevia berkembang di desa cibodas pasir jambu jawa barat, banyak petani yang belajar kesini, baik darri luar jawa maupun dari jawa sendiri, seperti garut. Walaupun stevia sendiri bukan tanaman utama, yang utama adalah kopi".

Selain dari itu sebagai petani kopi yang mengembangkan stevia mereka memiliki hubungan yang harmonis dan emosional dengan koperasi nukita, sehingga antara petani dengan koperasi ada ketergantungan emosional. Ketika pengembangan stevia unpad sudah disepakati oleh koperasi dan kelompok, petani mengikutinya. Terlebih secara ekonomi, pasar dari stevia dijamin oleh koperasi. Koperasi menjamin menampung produksi (jaminan pasar) yang dihasilkan petani.dan petanipun terobsesi dengan keuntungan substitusi dari stevia selain keuntungan dari kopi yang dibeli koperasi. "margi ieumah candak ti perguruan tinggi mudah2an jantenna sareng produksina sae, kantenan ieu aya damel babarengan sareng koperasi, abimah ngiringan bae...kantenan koperasi nampung hasil patani, pasarna di jamin...sok sanaos tangkal panyelang diantara kopi mudah-mudahan langkung untung..."

Dari informasi ini nampak, meskipun banyak yang kurang tertarik dengan koperasi, tapi ternyata di cibodas kab Bandung.

Koperasi sangat melindungi, melayani kebutuhan petani anggota. sehingga penting ketika akan mengembangkan suatu produk, bukan hanya uji lokasi tapi harus melibatkan pasar, dan ini bisa jadi stimulan bagi petani untuk ikut berpartisipasi baik secara ide, fisik, maupun financial.

\section{KESIMPULAN}

Simpulan. Partisipasi petani dalam pengembangan stevia diwujudkan dalam bentuk Ide /gagasan,fisik dan finasial. Partisipasi petani dalam pengembangan stevia, tidak terlepas dari dukungan koperasi yang berfungsi sebagai penampung hasil, kelompok sebagai tempat belajar, petani sebagai pelaku yang menjaga kuantitas dan kualitas produksi. Ketergantungan petani terhadap kopersai nukita, mendukung petani berpartisipasi

Stevia unpad yang dikembangkan di petani secara fisik kurang menarik karena cabangnya sedikit,dan daunnya kecil-kecil. Saran

Perlu rekayasa lanjutan terkait dengan pertumbuhan, cabang dan bentuk daun.

\section{DAFTARPUSTAKA.}

Budiarso, Irwan T.2008. Karsinogen Kimiawi dan Mikokarsinogen. Departemen Kesehatan R.I. Jakarta.

David Berry,1983 Pokok-pokok Pikiran Dalam SOSIOLOGI. Diterjemahkan oleh Lembaga Pendidikan dan Pengembangan Sosiologi. Disunting Oleh Paulus Wirutomo. Penerbit Rajawali Jakarta.

David Krech, Richard S. Crutchfield and Egerton L.Ballachey,1962 Indivual In Society a TextBook of Social Psichology. University of California Berkeley. McGraw-Hill International Book Company

Dika Supyandi,Yayat Aukayat, Medi Rahmadi,2016 Integrasi Participatory Plant Breeding dan Freferensi konsumen : Peluang Penerapannya dalam Pengembangan Varietas Kedelai Baru di Indonesia. AGRICORE, Jurnal Agribisnis dan Sosial Ekonomi Pertanian Unpad, Voleme 1 Nomer 1 Juni 2016.

Doyle Paul Johnson, 1981. Teori Sosiologi Klasik dan Modern di Indonesiakan oleh Robert M Z Lawang. Penerbit Gramedia Jakarta.

Homan, George C, Social Behavior, Its Elementary Forms, New York: Harcourt, Brace,and World, 1961; revised edition, New York : Harcourt, Brace,Juvanovich 1974 
James C. Scott,1981 Moral Ekonomi Petani. Terjemahan Yayasan Ilmu-ilmu sosial . Penerbit LP3ES Jakarta

Margono Slamet, 1985 Pengantar Sosiologi,CV. Rajawali, Jakarta

Maria, 2009 Analisis Kebijakan Tataniaga Gula terhadap ketersediaan dan Harga Domestik Gula Pasir di Indonesia. Pusat Analisis Sosial Ekonomi dan Kebijakan Pertanian, Badan Penelitian dan Pengembangan Pertanian, Departemen Pertanian.

Maudy E., Paimin, dan Fendy R. 1992. Budidaya Stevia. Trubus, No. 274 Tahun XXIII, hal. 22-23

Max Weber, 1984, The Protestant Ethic and the Spirit of Capitalism.UNWIM PAPERBACKS. London

Popkin.Samuel L,1979. The Rational Peasant.Universty of California Press. Berkeley*Los Angeles* London

Rogers Everett M, Shoemaker F Flyd,1987. Memasyarakatkan Ide-ide Baru, disrikan oleh Abdillah Hanafi. Penerbit Usaha Nasional Surabaya -Indonesia

Suseno Amin, 2015 Suseno Amien, Sarifah Nurjanah, dan Hepi Hapsari. 2015. Seleksi Hasil dan Kompenen Tanaman Stevia Hasil Mutasi in Vitro untuk Memenuhi Kebutuhan Gula Rendah Kalori Nasional. Laporan Penelitian Strategis Nasional, UNPAD. Belum dipublikasi.

Totok Marikanto, 1982 Penyuluhan Pertanian dalam Teori dan Praktek. Lembaga Studi Pembangunan Pertanian dan Pedesaan (LSP3),Penerbit HAPSARA Surakarta

Yayat sukayat, 1994. Partisipasi Petani Dalam Penatagunaan Air di Tingkat Usahatani. Thesis S2 Unpad.

Ulber Silalahi, 2012 Metode Penelitian Sosial .PT Refika Aditama Bandung. 
Vol. 3, No. 1, Juli 2018

AGRICORE:Jurnal Agribisnis dan Sosial Ekonomi Pertanian 